\title{
Deformation and Grain Growth of Low-Temperature-Sintered High-Purity Alumina
}

\author{
Liang A. Xue* and I-Wei Chen* \\ Department of Materials Science and Engineering, The University of Michigan, \\ Ann Arbor, Michigan 48109-2136
}

\begin{abstract}
Through close control over green-state powder processing, pure alumina ceramics of $0.5-\mu \mathrm{m}$ grain size were obtained by sintering at $1250^{\circ} \mathrm{C}$. The static grain growth of this material was modest at temperatures below $1300^{\circ} \mathrm{C}$. However, dynamic grain growth occurred rapidly during superplastic deformation. Therefore, although the ultrafine-grained alumina exhibited rather low initial flow stress at relatively low deformation temperatures, dynamic grain-growth-induced strain hardening gave rise to high flow stress causing cavitation and cracking. As a result, superplastic deformation could not be achieved for the ultrafine-grained pure alumina. [Key words: alumina, deformation, grain growth, processing, microstructure.]
\end{abstract}

\section{Introduction}

$\mathbf{T}$ HERE have been extensive studies in the literature on the high-temperature deformation of $\mathrm{Al}_{2} \mathrm{O}_{3}$ ceramics. ${ }^{1-15}$ Their deformation can generally be expressed by the following equation:

$$
\dot{\varepsilon}=A \sigma^{n} d^{-p} \exp (-Q / R T)
$$

where $\dot{\varepsilon}$ is the strain rate, $A$ is a constant, $\sigma$ is the flow stress, $n$ is the stress exponent, $d$ is the grain size, $p$ is the inverse grain size exponent, $Q$ is the activation energy, and $R$ and $T$ have their usual meanings. For fine-grained alumina, Cannon et al.'s work ${ }^{9}$ has shown that $n=2, p=2$, and $Q=470 \mathrm{~kJ} / \mathrm{mol}$ can represent deformation data at low stress range reasonably well. Of these studies, non-steady-state deformation has been reported in some instances, ${ }^{8-14}$ due to grain growth or cavitation.

The smallest grain size of alumina employed in previous deformation studies was about $1 \mu \mathrm{m}$. According to these studies, one may predict that at an even smaller grain size, say, $0.25 \mu \mathrm{m}$, superplasticity with a strain rate of $10^{-4} / \mathrm{s}$ may be achieved at $60 \mathrm{MPa}$ and $1250^{\circ} \mathrm{C}$, provided that the microstructure remains stable during deformation. This view is encouraged by recent sintering studies ${ }^{16,17}$ which reported such a fine-grained alumina and which also showed a considerably reduced grain growth rate at $\sim 1300^{\circ} \mathrm{C}$ and below. For example, at $1340^{\circ} \mathrm{C}$, an alumina sample with a starting particle size of $0.4 \mu \mathrm{m}$ reaches $98 \%$ of the theoretical density in $6 \mathrm{~h}$, and it grows to have a grain size of only $1.5 \mu \mathrm{m}$ during the next $42 \mathrm{~h}$. When the starting particle size is reduced to $0.1 \mu \mathrm{m}$, high-purity alumina with a grain size of $0.25 \mu \mathrm{m}$ can be sintered at $1150^{\circ} \mathrm{C} .{ }^{17}$ It remains to be seen whether dynamic grain growth induced by deformation will occur at these low tem-

R. Raj-contributing editor

\footnotetext{
Manuscript No. 197442. Received July 12, 1990; approved September 13, 1990.

Supported by the U.S. Army Research Office under Contract No. DAAL03-89-K0133.

*Member, American Ceramic Society.
}

peratures. We have therefore investigated a low-temperaturesintered high-purity alumina to examine its deformation behavior and microstructural evolution.

\section{Experimental Procedure}

The starting material was a high-purity $(>99.99 \%)$ alumina powder ${ }^{\dagger}$ with an average particle size of $\sim 0.2 \mu \mathrm{m}$. The powder was dispersed in distilled water by attrition-milling for $30 \mathrm{~min}$ in an alumina jar using alumina milling balls with a surfactant (Darvan 821A). ${ }^{\ddagger}$ This was followed by ultrasonic agitation.

To determine the best rheological condition for slip casting, the viscosity of the slurry was measured with a cone/plate viscometer. ${ }^{\S}$ The surfactant content which gave the lowest viscosity, and hence the best casting condition, was sought. ${ }^{18}$ To be representative of the slip casting state, particularly the one at the interface between the suspension and the sedimentated cake, a high (38 vol\%) solid loading was used for the slurry. Figure 1 shows the relation between viscosity and Darvan concentration at various shear rates $(\dot{\gamma})$ for this slurry. A steep minimum is seen at every shear rate, at around $0.014 \mathrm{~cm}^{3}$ of Darvan $/(\mathrm{g}$ of alumina). This content of surfactant was used in our subsequent work. The slurry was then cast, under pressure up to $1 \mathrm{MPa}$, into cakes of $47-\mathrm{mm}$ diameter, which were dried first in air and then in an oven at $130^{\circ} \mathrm{C}$. These cakes were sintered in air at temperatures ranging from $1250^{\circ}$ to $1300^{\circ} \mathrm{C}$ for a time up to $4 \mathrm{~h}$.

${ }^{\dagger}$ TM-D, Taimei Chemicals, Tokyo, Japan

${ }^{\ddagger}$ Darvan 821A, R. T. Vanderbilt Co. Inc., Norwalk, CT.

${ }^{8}$ Model DV-II, Brookfield Engineering Labs Inc., Stoughton, MA.

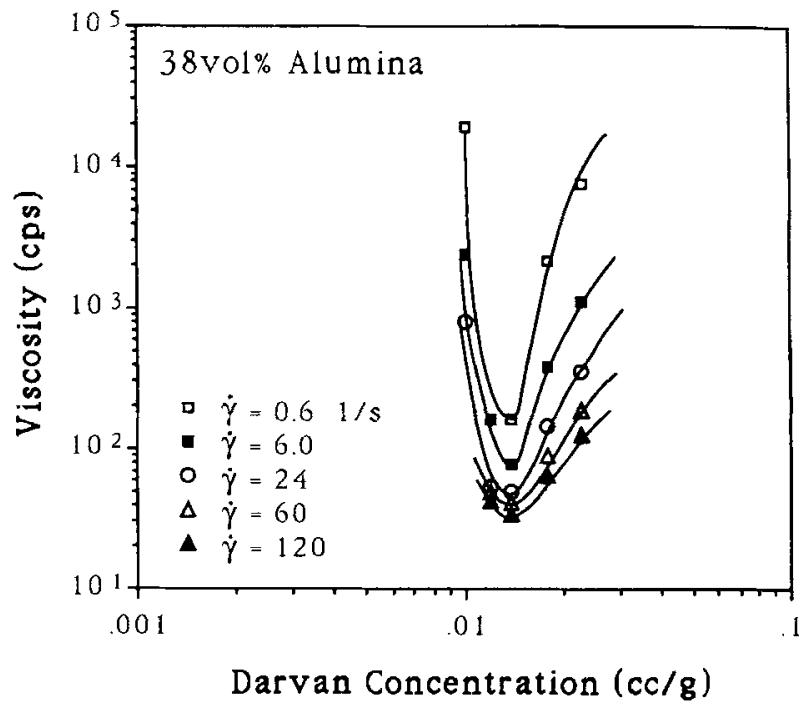

Fig. 1. Relationship between viscosity and surfactant concentration of a slurry containing 38 vol\% alumina. 


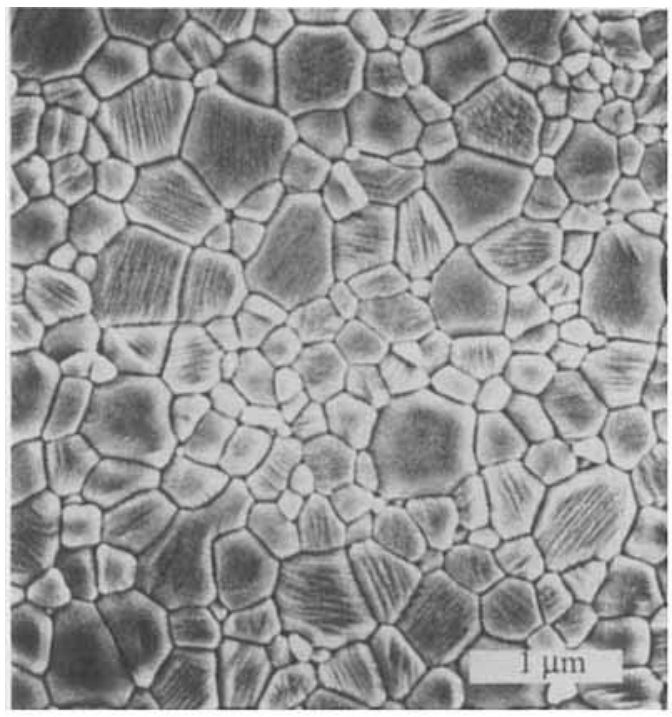

(A)

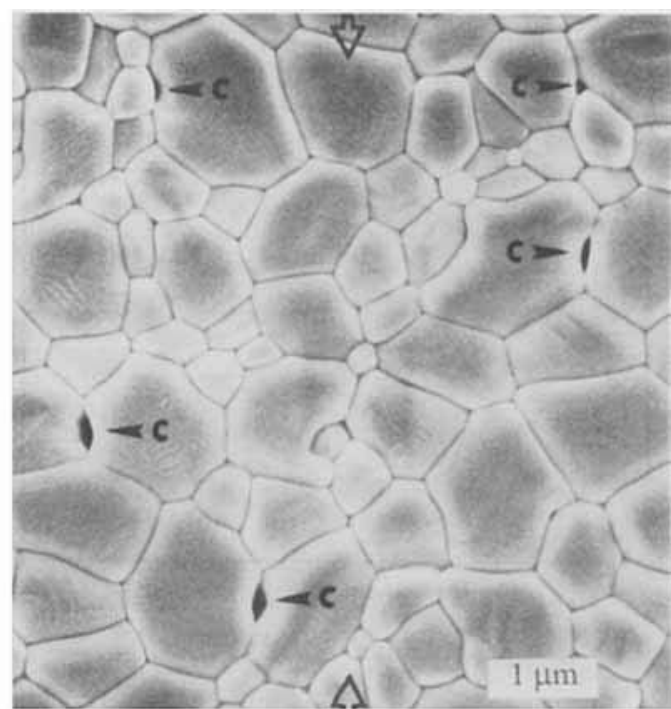

(B)

Fig. 2. Scanning electron micrograph of alumina: (A) as-sintered $\left(1250^{\circ} \mathrm{C}, 4 \mathrm{~h}\right),(\mathrm{B})$ deformed at $1250^{\circ} \mathrm{C}\left(\dot{\varepsilon}=1.5 \times 10^{-5} \mathrm{~s}^{-1} ; \varepsilon=0.3\right)$. The compression axis is shown by hollow arrows, and cavities are indicated by solid arrows.

The density of the sintered material was determined by water immersion. Specimens with densities greater than $98 \%$ of the theoretical were used in the deformation study. Microstructures of the sintered and/or deformed specimens were characterized by SEM. The grain size was obtained by multiplying the average linear intercept length of at least 500 grains by 1.56 . For deformed specimens, measurements were taken at directions both parallel and perpendicular to the axis of the applied stress, and the average was used. Static grain growth data were obtained from dummy specimens placed next to a deforming sample, and also from separately annealed specimens.

Specimens for the deformation tests were cut into square bars with an aspect ratio of 2.2. Deformation was conducted in uniaxial compression in air, between $1250^{\circ}$ and $1400^{\circ} \mathrm{C}$, with strain rates from $4 \times 10^{-6}$ to $1.5 \times 10^{-3} / \mathrm{s}$, in a platinum furnace. Other experimental details were similar to the one reported elsewhere. ${ }^{19}$

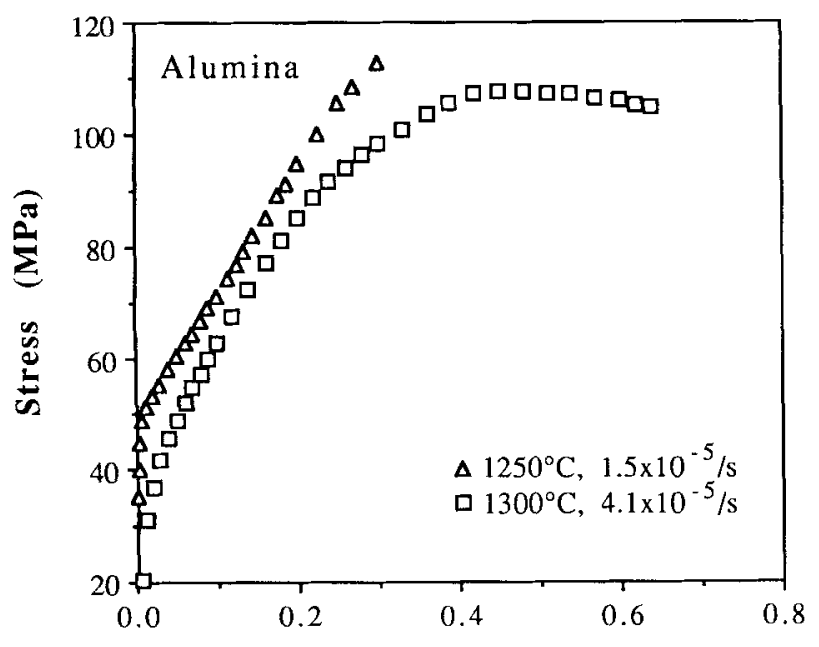

True Strain

Fig. 3. True stress as a function of true strain at two different temperatures.

\section{Results and Discussion}

\section{(1) Sintered Microstructure}

A polished cross section of a sintered specimen $\left(1250^{\circ} \mathrm{C}\right.$ for $4 \mathrm{~h}$ ) is shown in Fig. 2(A). The average grain size of this specimen is $0.5 \mu \mathrm{m}$. Note that the grains revealed seem to fall

Table I. Flow Stress of High-Purity Alumina at Two Strains for Various Deformation Conditions

\begin{tabular}{ccccc}
\hline \multicolumn{2}{c}{ Deformation conditions } & \multicolumn{2}{c}{ Flow stress $(\mathrm{MPa})$} \\
\cline { 2 - 3 } Temperature $\left({ }^{\circ} \mathrm{C}\right)$ & Strain rate $\left(\times 10^{-4} / \mathrm{s}\right)$ & & $\varepsilon=2 \%$ & $\varepsilon=25 \%$ \\
\hline 1250 & 0.15 & 53 & 105.5 \\
1300 & 0.41 & 36 & 93 \\
1300 & 1.0 & 61.5 & 109.6 \\
1350 & 1.8 & 46 & 102.8 \\
1400 & 1.0 & 22.3 & 103 \\
1400 & 2.4 & 35 & 104 \\
\hline
\end{tabular}

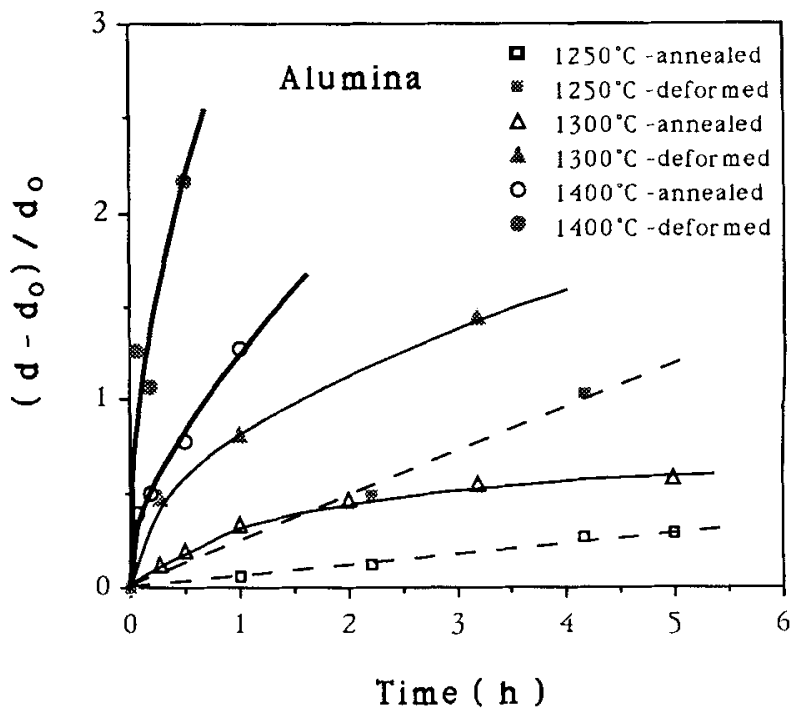

Fig. 4. Comparison of grain growth during static annealing and during deformation at various temperatures. 


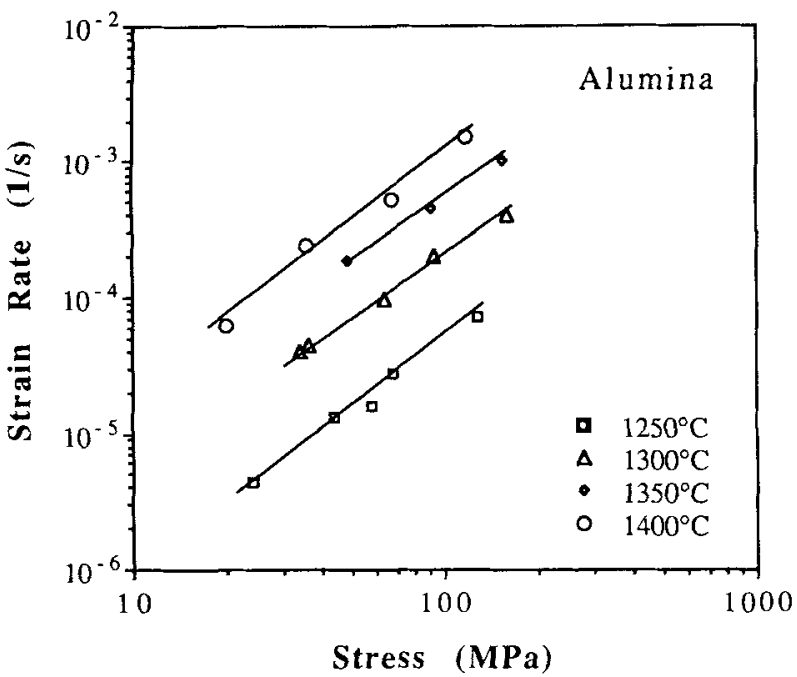

(A)

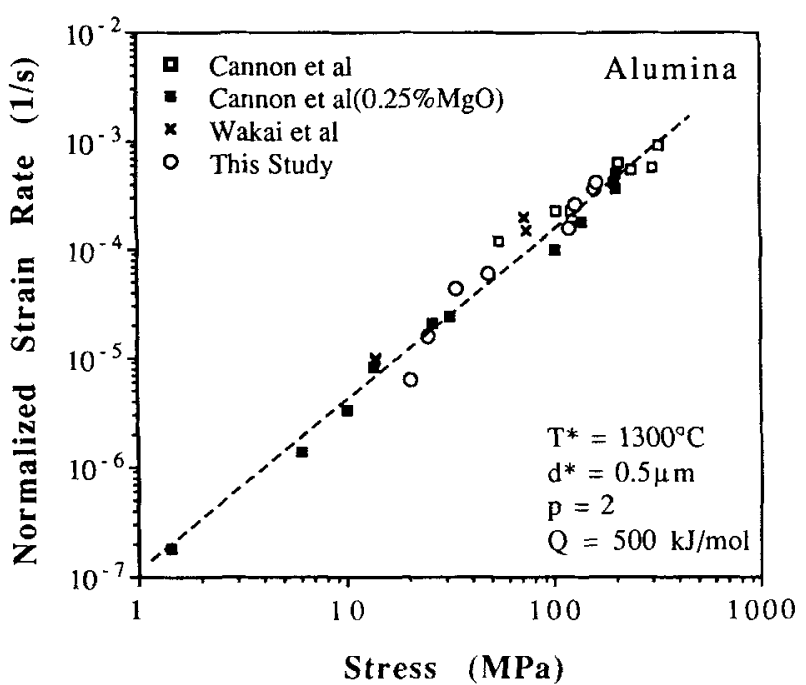

(B)

Fig. 5. (A) Relationship between strain rate and flow stress at various temperatures. (B) Normalized strain rate versus flow stress for finegrained alumina from various studies. References and grain sizes are Cannon ${ }^{9}(1.25 \mu \mathrm{m}$ for both pure and $\mathrm{MgO}-\mathrm{doped})$, Wakai ${ }^{15}(0.96 \mu \mathrm{m}$ pure). The symbols indicated the end points of the data range for one deformation temperature and one material. The grain sizes cited here are 1.56 times the average linear intercept distance between grain boundaries.

into two size groups, similar to the ones in the micrograph of a recent sintering study cited earlier. ${ }^{17}$ (Although the latter work demonstrated a grain size as small as $0.25 \mu \mathrm{m}$, it also required the use of a specially classified ultrafine powder $(0.1 \mu \mathrm{m})$ obtained by suspension processing. (This procedure is deemed to have too low a yield for deformation studies.) The larger grains are of $1-\mu \mathrm{m}$ size, which are still finer than those in most of the materials employed in previous studies.

\section{(2) Deformation and Grain Growth}

Typical true stress versus true strain curves at two different temperatures are shown in Fig. 3. Extensive strain hardening was evident under these and other testing conditions. Table I lists, as examples, flow stress values at strains of $2 \%$ and $25 \%$ for some temperatures and strain rates. In all cases, flow stress has increased by at least a factor of 2 between these two strains. The corresponding microstructure of the specimen deformed at $1250^{\circ} \mathrm{C}$ of Fig. 3 is given in Fig. 2(B), showing considerable grain growth and some cavities compared to Fig. 2(A). Thus, the strain hardening can be attributed to grain growth. At higher strains and flow stress above $100 \mathrm{MPa}$ or so, cavitation was severe and often caused a load drop.

We found much of the grain growth observed was induced by deformation. This is verified by comparing grain growth data during static annealing and during deformation, as shown in Fig. 4. The grain size increment is normalized as $\left(d-d_{0}\right) / d_{0}$, where $d_{0}$ is the initial grain size, and plotted against the deformation time or annealing time. These data show that although static grain growth of this material at temperatures below $1300^{\circ} \mathrm{C}$ is very slow, the grain growth during deformation, i.e., dynamic grain growth, is much faster even at temperatures as low as $1250^{\circ} \mathrm{C}$. Similar observations have been made previously at higher temperatures, e.g., for $\mathrm{MgO}-$ doped alumina at $1420^{\circ} \mathrm{C}^{11}$ and $1450^{\circ} \mathrm{C}^{10}$ and for $\mathrm{MgO}-\mathrm{Cr}_{2} \mathrm{O}_{3}$ or $\mathrm{MgO}-\mathrm{Y}_{2} \mathrm{O}_{3}$ codoped alumina at $1450^{\circ}$ to $1550^{\circ} \mathrm{C} .^{7,14}$ (Dynamic grain growth in these doped materials was less pronounced than that observed in our study, presumably because of solute effects and larger grain sizes.)

\section{(3) Comparison with Previous Studies}

The data of strain rate and flow stress are plotted on a logarithmic scale in Fig. 5(A) at different deformation temperatures. To reduce the influence of grain growth, flow stress at $2 \%$ strain was used here. The stress exponent $n$ found from the slopes is about 1.7 , which is in reasonably good agreement with the $n$ values of 1.5 to 2 reported for fine-grained alumina., ${ }^{9,13,15}$ From the temperature dependence of strain rate, the activation energy is calculated to be $460 \mathrm{~kJ} / \mathrm{mol}$, which lies in the low range of 410 to $625 \mathrm{~kJ} / \mathrm{mol}$ found for alumina., ${ }^{9,13,14}$

To better compare our data of very fine-grained alumina with those of other studies, ${ }^{9,15}$ we have plotted these data in Fig. 5(B) at a normalized grain size $d^{*}=0.5 \mu \mathrm{m}$ and $T^{*}=1300^{\circ} \mathrm{C}$, using $p=2$ and $Q=500 \mathrm{~kJ} / \mathrm{mol}$ in Eq. (1) for conversion. Overall, the data are in good agreement with each other. Thus, the ultrafine-grained high-purity alumina apparently deforms by the same mechanism despite its unstable microstructure.

\section{Conclusions}

Deformation of high-purity alumina with a grain size of $0.5 \mu \mathrm{m}$ or smaller is dominated by dynamic grain growth, which is pronounced at temperatures as low as $1250^{\circ} \mathrm{C}$. As a result, flow stress increases rapidly with strain. Therefore, in developing superplastic alumina, the suppression of dynamic grain growth is at least as crucial as the attainment of an ultrafine initial microstructure. Either solute drag or secondphase pinning may be utilized to accomplish this goal, as will be demonstrated in a future report.

\section{References}

${ }^{1}$ R. C. Folweiler, "Creep Behavior of Pore-Free Polycrystalline Aluminum Oxide," J. Appl. Phys., 32 [5] 773-78 (1961).

${ }^{2}$ T. Sugita and J. A. Pask, "Creep of Doped Polycrystalline Alumina," J. Am. Ceram. Soc., 53 [11] 609-13 (1970).

${ }^{3}$ S. I. Warshaw and F. H. Norton, "Deformation Behavior of Polycrystalline Aluminum Oxide," J. Am. Ceram. Soc., 45 [10] 479-86 (1962).

${ }^{4}$ A. H. Heuer, D. J. Sellers, and W. H. Rhodes, "Hot-Working of Aluminium Oxide: I. Primary Recrystallization and Texture," J. Am. Ceram. Soc., 52 [9] 468-74 (1969).

${ }^{5}$ R. M. Cannon and R. L. Coble, "Review of Diffusional Creep of $\mathrm{Al}_{2} \mathrm{O}_{3}$ "; pp. 61-100 in Deformation of Ceramic Materials. Edited by R. L. Bradt and R. E. Tressler. Plenum Press, New York, 1975.

${ }^{6}$ W. R. Cannon and O.D. Sherby, "Creep Behavior and Grain-Boundary Sliding in Polycrystalline $\mathrm{Al}_{2} \mathrm{O}_{3}$,"J. Am. Ceram. Soc., 60 [1-2] 44-47 (1977).

${ }^{7} \mathrm{C}$. Carry and A. Mocellin, "Superplastic Forming of AluminaProceedings of the 3rd Symposium on Fabrication Science," Proc. Br. Ceram. Soc., 33, 101-15 (1983).

${ }^{8} \mathrm{E}$. M. Passmore and T. Vasilos, "Creep of Dense, Pure, Fine-Grained Aluminum Oxide," J. Am. Ceram. Soc., 49 [3] 166-68 (1966).

${ }^{9}$ R. M. Cannon, W. H. Rhodes, and A. H. Heuer, "Plastic Deformation of Fine-Grained Alumina $\left(\mathrm{Al}_{2} \mathrm{O}_{3}\right)$ : I, Interface-Controlled Diffusional Creep," J. Am. Ceram. Soc., 63 [1-2] 46-53 (1980).

${ }^{10}$ J. D. Fridez, C. Carry, and A. Mocellin, "Effects of Temperature and 
Stress on Grain-Boundary Behavior in Fine-Grained Alumina"; pp. $720-40$ in Advances in Ceramics, Vol. 10, Structure and Properties of $\mathrm{MgO}$ and $\mathrm{Al}_{2} \mathrm{O}_{3}$ Ceramics. Edited by W. D. Kingery. American Ceramic Society, Columbus, $\mathrm{OH}, 1984$

${ }^{11} \mathrm{~K}$. R. Venkatachari and R. Raj, "Superplastic Flow in Fine-Grained Alumina," J. Am. Ceram. Soc., 69 [2] 135-38 (1986).

${ }^{i 2}$ A. H. Chokshi and J. R. Porter, "Analysis of Concurrent Grain Growth During Creep of Polycrystalline Alumina," J. Am. Ceram. Soc., 69 [2] C-37-C-39 (1986).

${ }^{13}$ A. H. Chokshi and J. R. Porter, "High Temperature Mechanical Properties of Single Phase Alumina," J. Mater. Sci., 21, 705-10 (1986).

${ }^{14} \mathrm{C}$. Carry and A. Mocellin, "Structural Superplasticity in Single Phase Crystalline Ceramics," Ceram. Int., 13, 89-98 (1987).
${ }^{15} \mathrm{~F}$. Wakai, T. Iga, and T. Nagano, "Effect of Dispersion of $\mathrm{ZrO}_{2}$ Particles on Creep of Fine-Grained $\mathrm{Al}_{2} \mathrm{O}_{3}$," J. Ceram. Soc. Jpn., 96 [12] 1206-209 (1988).

${ }^{16}$ T-S. Yeh and M.D. Sacks, "Effect of Particle Size Distribution on the Sintering of Alumina," J. Am. Ceram. Soc., 71 [12] C-484-C-487 (1988).

${ }^{17}$ T-S. Yeh and M. D. Sacks, "Low-Temperature Sintering of Aluminium Oxide," J. Am. Ceram. Soc., 71 [10] 841-44 (1988).

${ }^{18} \mathrm{~J}$. Cesarano III and I. A. Aksay, "Processing of Highly Concentrated Aqueous $\alpha$-Alumina Suspensions Stabilized with Polyelectrolytes," J. Am. Ceram. Soc., 71 [12] 1062-67 (1988).

${ }^{19} \mathrm{C}$ - M. J. Hwang and I-W. Chen, "Effect of a Liquid Phase on Superplasticity of $2-\mathrm{mol}_{\%}-\mathrm{Y}_{2} \mathrm{O}_{3}$-Stabilized Tetragonal Zirconia Polycrystals," J. Am. Ceram. Soc., 73 [6] 1626-32 (1990). 